\title{
Temporal isotope changes in wet snow layers in association with mass exchange between snow particles and liquid water in between the particles
}

\author{
S. HASHIMOTO, S. ZHOU, M. NAKAWO, M. SHIMIZU, N. ISHIKAWA \\ Hydrospheric Research Center, Nagoya University, Furo-cho, Chikusa-ku, Nagoya 464-8601, Japan \\ E-mail: hashi@nagoya-u.ac.jp
}

\begin{abstract}
We carried out snow-pit observations at Nagaoka, Niigata prefecture, Japan, where the snow layers were at the melting point. It was observed that the water content in the snowpack was nearly constant at approximately $10 \%$, and the coarsening rate of snow particles was about $0.4 \times 10^{-3} \mathrm{~mm}^{3} \mathrm{~h}^{-1}$, which was in the range between the rate for dry snow and that for snow soaked in water. The isotope change of snow particles by melting and freezing in a closed system under isothermal conditions at $0^{\circ} \mathrm{C}$ was modeled. The temporal change in isotope concentration was calculated for wet snow layers, based on the fractionation between snow particles and liquid water in between the particles, in association with the coarsening of snow particles. The results compared well with field observations. These results suggest that the isotope concentration of the pore water that flows downward from the surface contributed significantly to the isotope change of snow particles.
\end{abstract}

\section{INTRODUCTION}

Ice-core studies are one of the most promising methods of reconstructing the past climate and environment (e.g. Shoji and Langway, 1989). In particular, isotope concentrations in polar ice cores have been used as indicators of past temperatures (e.g. Robin, 1983). More recently, studies have been made not only with polar ice cores but also with ice cores from glaciers at low and middle latitudes (Thompson and others, 1988; Aizen and others, 1996). Krouse and others (1977), however, reported that isotope profiles were homogenized in wet snowpacks, although there was no significant change over time in snowpacks in the dry-snow zone nor in the superimposed-ice zone. It is therefore necessary to examine the temporal change of the isotope concentration, which could occur during melting or freezing in wet snow layers, for the ice-core analysis obtained from these areas.

Raymond and Tusima (1979) reported that in a wet snowpack at $0^{\circ} \mathrm{C}$ relatively small particles shrink by melting and large particles grow by freezing, due to the grain curvature effect, and that these processes take place simultaneously. They also found that the amount of small particles

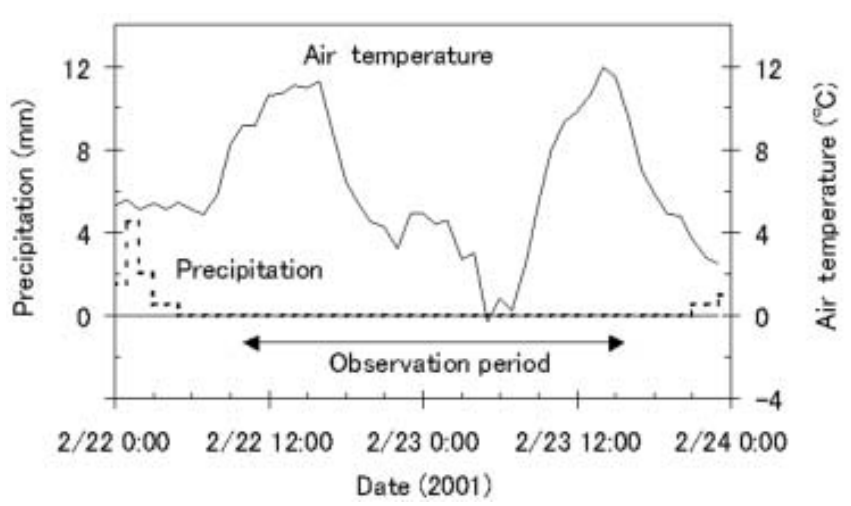

Fig. 1. Precipitation and air temperature during the observation period at Nagaoka, 22-23 February. melting is identical to the amount of water freezing to large particles. This amount is henceforth called the 'exchange mass'. The isotope fractionation during melting can be ignored because the self-diffusion coefficient is very small in ice matrices (e.g. Jouzel and Souchez, 1982; Nakawo and others, 1993). Thus, the freezing process is considered to be solely responsible for the change in isotope concentration in wet snow.

Within the internal layers of a snowpack under isothermal conditions at $0^{\circ} \mathrm{C}$, the isotope concentration in snow particles depends on the exchange mass that is expressed as a function of snow-particle growth rate and time (Nakawo and others, 1993). Although the growth rate of snow particles is considered to be a function of the water content, the relation between them has not been clarified. This research investigates the relationship between snow-particle growth rate and water content, based on which temporal isotope change of snow particles is calculated, and compared with the observed result given in Hashimoto and others (2002) in order to analyze the isotope change processes occurring during the snowmelt season.

\section{OBSERVATION}

Field observations were carried out at Nagaoka facing the Sea of Japan, central Japan, from $1000 \mathrm{~h}$ (local time) on 22 February to $1600 \mathrm{~h}$ on 23 February 2001. During the observation period, the snow temperature was $0^{\circ} \mathrm{C}$ throughout the snowpack. Snow depth at $1000 \mathrm{~h}$ was $109 \mathrm{~cm}$ on 22 February and $105.5 \mathrm{~cm}$ on 23 February. On both days, the water content at four heights in the snow cover, 95, 88, 50 and $10 \mathrm{~cm}$ above the ground, was measured at intervals of 1-2 hours from 1000 to $1600 \mathrm{~h}$ using a Toikka snow fork. Snow liquid-water content was measured about 10 times per day at each of the above-mentioned heights above the soil surface. The measurement accuracy was $0.5 \%$. Snow liquidwater content was assumed to be nearly constant for all layers, because no water channels were observed in the snow cover as suggested by Wakahama and others (1968). Snow particles were sampled at the same heights as for 

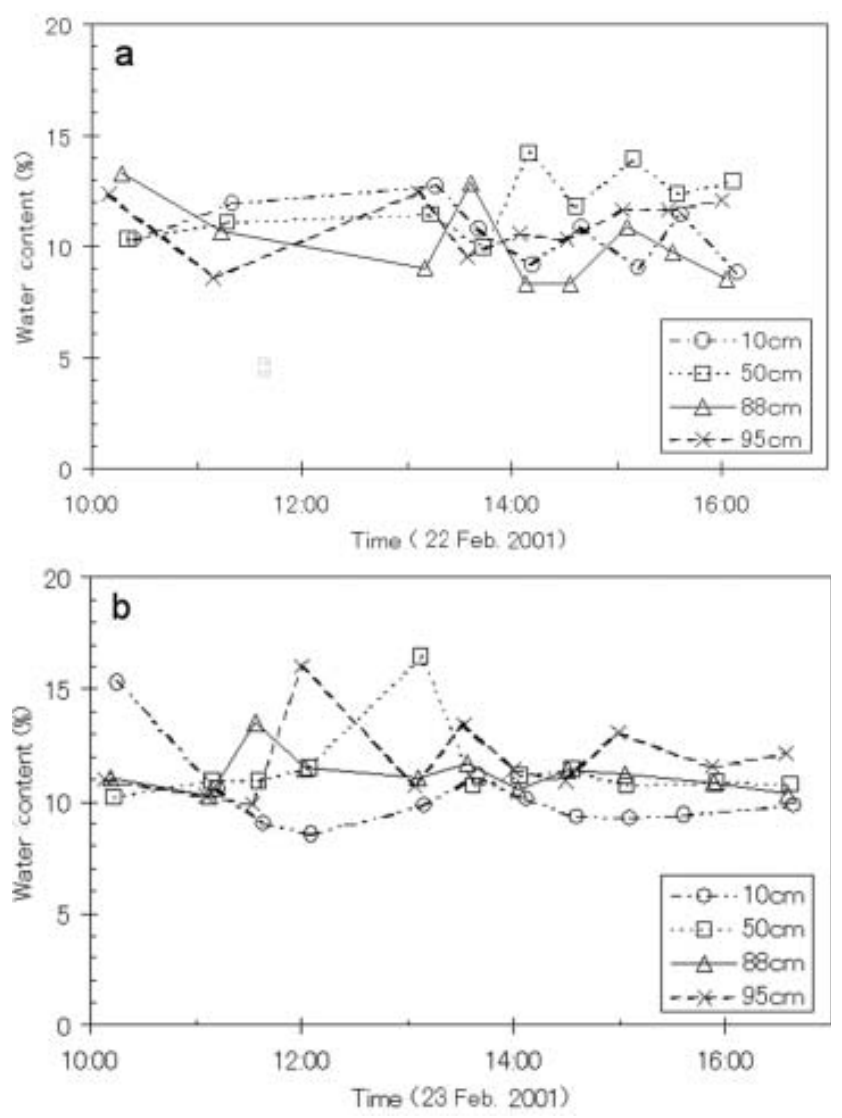

Fig. 2. Diurnal variation of water content in snow cover at different heights above the ground: (a) 22 February, (b) 23 February.

water content measurement, and particle sizes were measured by photographing the samples. Photography of snow particles was performed in the field. The photographs were later scanned and computer analyzed to determine the projected area of each particle. The snow particle size was defined as the sphere whose radius is the same as that of a circle whose area had been obtained by computer analysis. The measurement accuracy was $0.02 \mathrm{~mm}^{3}$.

Figure 1 shows the variation of air temperature and precipitation over the course of the observation period. There were no precipitation events during the observation period. The air temperature was about $0^{\circ} \mathrm{C}$ on the morning of 23 February. Wakahama and others (1968) observed that the water content in snow cover was nearly constant except near the snow surface layer even when air temperature fell below the freezing point.

\section{RESULTS}

\subsection{Diurnal variation of water content}

The water content at each observation height is shown in Figure 2 for the 2 days. The water-content peaks were $1300 \mathrm{~h}$ at $95 \mathrm{~cm}, 1330 \mathrm{~h}$ at $80 \mathrm{~cm}$, and $1400 \mathrm{~h}$ at $50 \mathrm{~cm}$ on 22 February, indicating that liquid water formed by melting at the snow surface and then gradually flowed downward. The average water contents at the four observation heights were $10.4 \%(95 \mathrm{~cm}), 11.7 \%(88 \mathrm{~cm}), 10.7 \%(50 \mathrm{~cm})$ and $11.5 \%(10 \mathrm{~cm})$ (Table 1$)$. The standard deviation of each average value was 1.6. The water content can be regarded as remaining constant around the mean value, although it fluctuated between a maximum of $16.4 \%$ (at $1300 \mathrm{~h}$ on

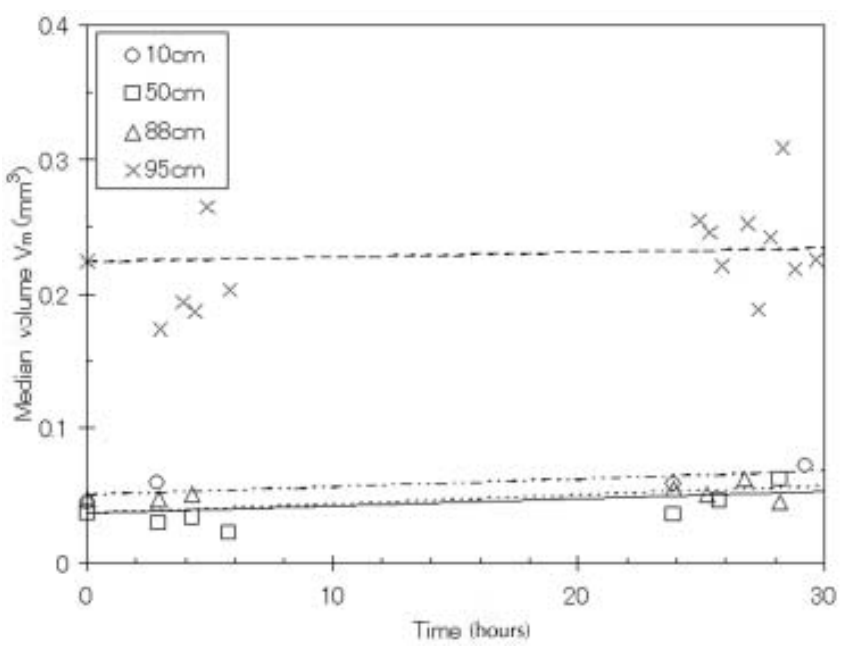

Fig. 3. Variation of the median volume $V_{\mathrm{m}}$ of snow particles at each height above the ground. Time $0=1000 \mathrm{~h}$ local time $($ UTC +0900$)$, 22 February.

23 February at $50 \mathrm{~cm}$ ) and a minimum of $8.3 \%$ (at $1400 \mathrm{~h}$ on 22 February at $88 \mathrm{~cm}$ ). As shown in Figure $2 \mathrm{a}$ and $\mathrm{b}$, the mean water content in the snow was approximately $10 \%$.

\subsection{Growth speed of snow particles}

According to Raymond and Tusima (1979), the normalized cumulative frequency curve for the volume distribution of snow particles is approximated by

$$
\Psi^{*}\left(\frac{V}{V_{\mathrm{m}}}\right)=\left(1-\frac{a V}{b V_{\mathrm{m}}}\right)^{\frac{1}{a}},
$$

where $V$ is the volume of a particle, $V_{\mathrm{m}}$ is a median volume, that is the volume corresponding to the volume where the cumulative frequency curve of the snow particle volume becomes $50 \%$, and $a$ and $b$ are constants. $V_{\mathrm{m}}$ is assumed to increase with time for simplicity.

$$
V_{\mathrm{m}}=V_{0}+\gamma t
$$

where $V_{0}$ is median volume at time zero and $\gamma$ is the growth speed of particles (Raymond and Tusima, 1979). The median volume $V_{\mathrm{m}}$ at each height is shown in Figure 3. It is thought that the difference in initial volume in each layer occurred because the environment during snowfall differed from that after deposition. Figure 3 and Table 1 show the growth rates, $\gamma$, of particles measured at each height. The values are in the range $0.1-0.8\left(10^{-3} \mathrm{~mm}^{3} \mathrm{~h}^{-1}\right)$, similar to the values obtained by Hashimoto and others (2002).

Table 1. Results of growth speed of snow particles

\begin{tabular}{ccc}
\hline $\begin{array}{c}\text { Height above } \\
\text { the ground } \\
\mathrm{cm}\end{array}$ & Water content & $\begin{array}{c}\text { Growth speed } \\
\text { of particles } \\
10^{-3} \mathrm{~mm}^{3} \mathrm{~h}^{-1}\end{array}$ \\
\hline 95 & 10.4 & 0.1 \\
88 & 11.7 & 0.1 \\
50 & 10.7 & 0.7 \\
10 & 11.5 & 0.8 \\
Average & 11.1 & 0.4 \\
Std dev. & 0.6 & 0.4 \\
\hline
\end{tabular}




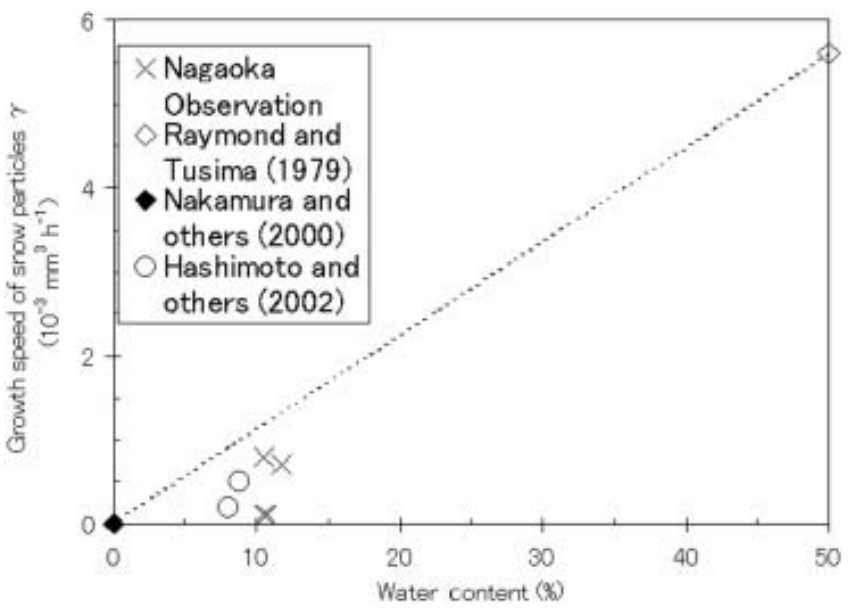

Fig. 4. Relationship between the growth speed of snow particles and water content (dotted line: the straight line that connected growth speed at $0 \%$ and at $50 \%$ ).

\subsection{Relation between snow particle growth rate and water content}

The relation between the growth speed of snow particles and water content is shown in Figure 4. The growth rates at water contents of $0 \%$ and $50 \%$ are $0.0040\left(10^{-3} \mathrm{~mm}^{3} \mathrm{~h}^{-1}\right)$ (Nakamura and others, 2000) and $5.6\left(10^{-3} \mathrm{~mm}^{3} \mathrm{~h}^{-1}\right)$ (Raymond and Tusima, 1979), respectively. Nakamura and others' result was obtained by analyzing 10 years of snow samples collected from Antarctica, and Raymond and Tusima's result was obtained through an experiment that preserved the bottle containing equivalent water and equivalent ice at $0^{\circ} \mathrm{C}$ in the laboratory. In the experiment, particle size measurement was performed three times during a period of 200 hours. As can be seen in Figure 4, the relation between the snow-particle growth rate and water content is nonlinear, although no data are available for $20-50 \%$ water content. Although the data scattered in a wide range, the growth rate of snow particles for water contents of $10 \%$ is about $0.4\left(10^{-3} \mathrm{~mm}^{3} \mathrm{~h}^{-1}\right)$, which is rather small compared with the value expected for $50 \%$ water content. This is in agreement with Wakahama's (1964) finding that the growth of snow particles is minimal in low water content.

\subsection{Relationship between the constant $a$ and water content}

As mentioned in section 1, relatively small particles shrink by melting and large particles grow by freezing in a wet snowpack at $0^{\circ} \mathrm{C}$, due to the particle curvature effect. Under isothermal conditions at $0^{\circ} \mathrm{C}$, the amount of melting of relatively small particles is identical with the amount of freezing of water on to large particles. The exchange mass, $f$, can be calculated by

$$
f=\beta \ln \left(1+\frac{\gamma}{V_{0}} t\right)
$$

where $\beta=[1 /(1+a)]^{1 / a}$, as indicated by Raymond and Tusima (1979).

The value obtained for $b$ in Equation (1) was 1.55 for both $0 \%$ and $50 \%$ water contents (Raymond and Tusima, 1979; Nakamura and others, 2000). However, the constant a differs as a function of water content: it is 0.14 (Nakamura and others, 2000) and 0.23 (Raymond and Tusima, 1979) for $0 \%$ and $50 \%$ water contents, respectively. The average value

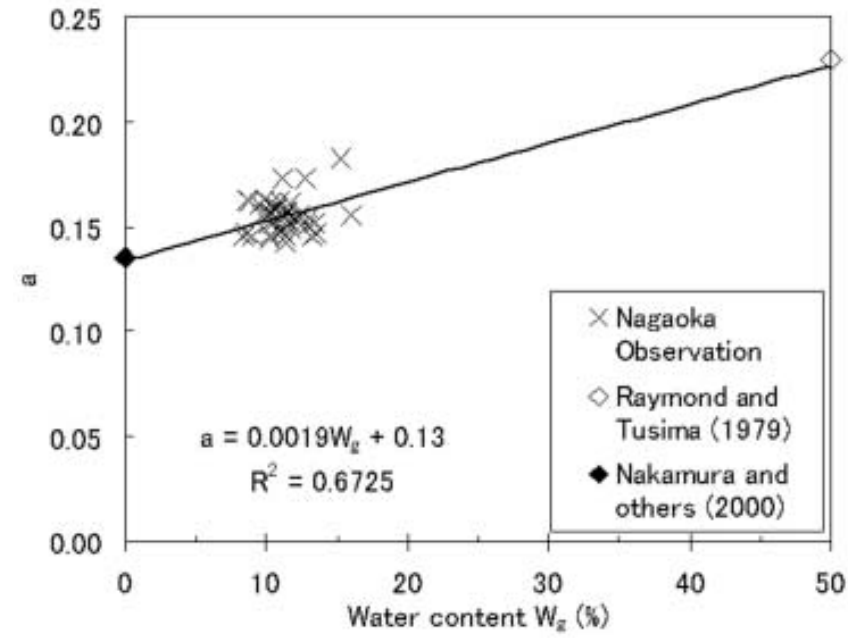

Fig. 5. Relationship between the constant $a$ and water content.

for a obtained in our observation was 0.15 (std dev.: 0.01) for $11.3 \%$ water content. The a value is plotted in Figure 5 for different water contents. It is found that a has a linear relation with water content $w_{g}(\%)$, which is expressed by

$$
a=0.0019 w_{g}+0.13 \text {. }
$$

\section{DISCUSSION}

\subsection{Isotope change in snow particles at $0^{\circ} \mathrm{C}$}

Model calculation of isotope change was performed by Nakawo and others (1993) for snow particles with 50\% water content. In our observation, however, the water content was about $10 \%$ in the snow cover, which is much lower than that used in the calculation by Nakawo and others (1993). The isotope concentration of the total ice fraction $\delta_{\mathrm{i} z}$ in wet snow with $100 \mathrm{wt} \%$ water content is given by

$$
\delta_{\mathrm{iz}}=\delta_{\mathrm{i} 0}(1-f)+\int_{0}^{f} \delta_{\mathrm{i}} \mathrm{d} f
$$

where $\delta_{\mathrm{i} 0}$ is the initial isotope concentration in snow particles and $\delta_{\mathrm{i}}$ is the isotope concentration of ice formed by refreezing water. Because of heavy-isotope fractionation during freezing, the isotope concentration of ice formed by refreezing of liquid water with isotope concentration $\delta_{\mathrm{w}}$ can be calculated by

$$
\alpha\left(1+\delta_{\mathrm{w}}\right)=1+\delta_{\mathrm{i}}
$$

The isotope fractionation is described in detail by Dansgaard (1964). The mass-conservation law gives

$$
\frac{\mathrm{d}}{\mathrm{d} f}\left[(1-w) \delta_{\mathrm{i} z}+w \delta_{\mathrm{w}}\right]=0 .
$$

From Equations (5-7)

$$
\begin{aligned}
\delta_{\mathrm{i}}=\delta_{\mathrm{i} 0}-\exp \left[-\alpha\left(\frac{1-w}{w}\right) f\right]\left[\left(\delta_{\mathrm{i} 0}+1\right)-\alpha\left(\delta_{\mathrm{w} 0}+1\right)\right] \\
\delta_{\mathrm{i} z}=\delta_{\mathrm{i} 0}+\frac{1}{\alpha}\left(\frac{w}{1-w}\right)\left[\left(\delta_{\mathrm{i} 0}+1\right)-\alpha\left(\delta_{\mathrm{w} 0}+1\right)\right] \\
\cdot\left\{\exp \left[-\alpha\left(\frac{1-w}{w}\right) f\right]-1\right\}
\end{aligned}
$$




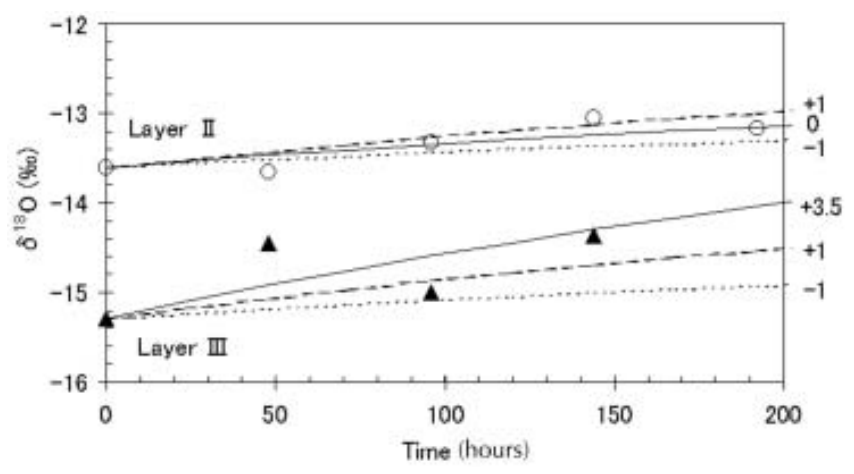

Fig. 6. Temporal isotope change of snow particles. O: layer II, $\mathbf{\Delta}$ : layer III. The values represent the difference between isotope concentrations in snow particles and pore water, $\left(\delta_{\mathrm{w} 0}-\delta_{\mathrm{i} 0}\right)$.

and

$$
\begin{aligned}
\delta_{\mathrm{w}}=\delta_{\mathrm{w} 0}+ & \frac{1}{\alpha}\left[\left(\delta_{\mathrm{i} 0}+1\right)-\alpha\left(\delta_{\mathrm{w} 0}+1\right)\right] \\
& \cdot\left\{1-\exp \left[-\alpha\left(\frac{1-w}{w}\right) f\right]\right\},
\end{aligned}
$$

where $\delta_{\mathrm{w} 0}$ is the initial isotope concentration of water, and $\alpha$ the isotope fractionation factor for the ice-water boundary at $0^{\circ} \mathrm{C}$. Using an isotope fractionation factor of 1.00291 for oxygen (Lehmann and Siegenthaler, 1991), we can calculate the isotope content for snow particles and water between the particles by Equations (9) and (10) respectively for a given value of $f$.

\subsection{Comparison with observations}

Figure 6 compares the result calculated by Equation (9) with the field observation data given by Hashimoto and others (2002). Layers III and II in the figure were located completely inside the snowpack during the observation period and were isothermal at $0^{\circ} \mathrm{C}$ (Hashimoto and others, 2002).

In the calculation, a value of 0.15 was used for a (Fig. 5) and $0.4 \times 10^{-3} \mathrm{~mm}^{3} \mathrm{~h}^{-1}$ for $\gamma$, which corresponds to a water content of $10 \%$. The following data were also used for the calculation based on the observation results (Hashimoto and others, 2002): initial isotope content of ice $\delta_{\mathrm{i} 0}$ was $-13.6 \%$ and the initial volume of the particles $V_{0}$ was $0.14 \mathrm{~mm}^{3}$ for layer II; $\delta_{\mathrm{i} 0}$ was $-15.3 \%$ and $V_{0}$ was $0.1 \mathrm{~mm}^{3}$ for layer III; $\delta_{\mathrm{w} 0}$ was $-14.6 \%$ or layer II and $-16.3 \%$ or for layer III. Hashimoto and others (2002) observed that the isotope content of liquid water, $\delta_{\mathrm{w} 0}$, is smaller than the isotope content of ice by about $1 \%$. A $1 \%$ difference between isotope concentrations in snow particles and in pore water was therefore assumed in the calculation.

The results of the calculation are shown with dotted lines in Figure 6. The calculated results predict smaller changes in isotope content, for both layers, than the observations. This may be because the pore water in reality was meltwater generated at the snow surface that had flowed downward, but the calculation neglects the water movement by assuming an isolated system with snow and water.

Figure 7 shows the isotope content profiles for liquid and solid observed by Hashimoto and others (2002). As mentioned above, isotope content is about 1\%o larger in water's solid phase than in its liquid phase, at the same height. The isotope content of water near the surface that would flow downward, however, is much greater than the isotope content in the solid phase in layer III by about 3-4\%.

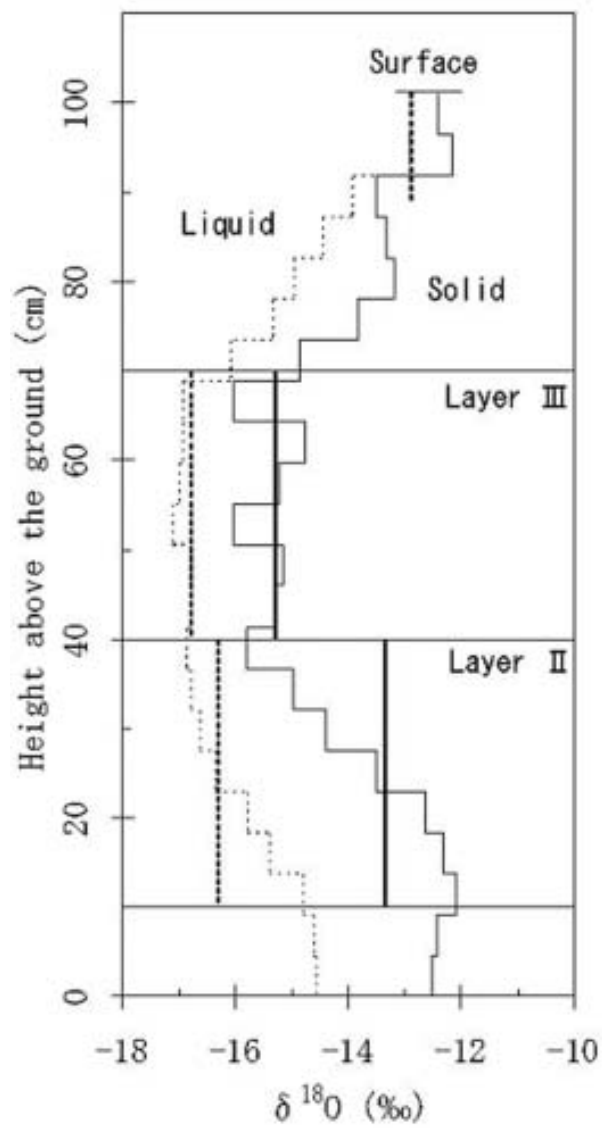

Fig. 7. Isotope profiles in the snow cover on 2 April (from Hashimoto and others, 2002). Solid line: snow particles; dotted line: pore water; dashed line: pore water at surface layer.

On the other hand, the isotope content for the solid phase in layer II is almost equivalent to the content for the liquid phase in the surface layer.

The model calculation was therefore made with the condition that isotope content is greater in the liquid phase by $3.5 \%$ than in the solid phase for layer III, and that isotope content is the same for the liquid phase and the solid phase for layer II. The results are shown in Figure 6 with solid lines. The recalculation is in good agreement with the observations, indicating that we must take into account the liquid water that flowed downward from the surface.

The model calculation, however, is based on Equation (9), which is applicable only to a closed system. Further modeling work is required that will take into account the water percolation process combined with the isotope fractionation process.

\section{ACKNOWLEDGEMENT}

We wish to thank the staff of the Nagaoka Institute of Snow and Ice Studies.

\section{REFERENCES}

Aizen, V., E. Aizen, J. Melack and T. Martma. 1996. Isotopic measurements of precipitation on central Asian glaciers (southeastern Tibet, northern Himalayas, central Tien Shan). J. Geophys. Res., 101(D4), 9185-9196.

Dansgaard, W. 1964. Stable isotopes in precipitation. Tellus, 16(4), 436-468. 
Hashimoto, S. and 6 others. 2002. Isotope studies of inner snow layers in a temperate region. Hydrol. Process., 16, 2209-2220.

Jouzel, J. and R.A. Souchez. 1982. Melting-refreezing at the glacier sole and the isotopic composition of the ice. J. Glaciol., 28(98), $35-42$.

Krouse, H.R., K. West, R. Hislop, H.M. Brown and J.L. Smith. 1977. Climatic and spatial dependence of the retention of $\mathrm{D} / \mathrm{H}$ and $\mathrm{O}^{18} / \mathrm{O}^{16}$ abundances in snow and ice of North America. International Association of Hydrological Sciences Publication 118 (Symposium at Grenoble 1975 - Isotope and Impurities in Snow and (ce), 242-247.

Lehmann, M. and U. Siegenthaler. 1991. Equilibrium oxygen- and hydrogen-isotope fractionation between ice and water. J. Glaciol., 37(125), 23-26.

Nakamura, K., M. Nakawo, Y. Ageta, K. Goto-Azuma and K. Kamiyama. 2000. Post-depositional loss of nitrate in surface snow layers of the Antarctic Ice Sheet. Bulletin of Glaciological Research, Data Center for Glacier Research, Japanese Society of Snow and Ice, 17, 11-16.

Nakawo, M., S. Chiba, H. Satake and S. Kinouchi. 1993. Isotopic fractionation during grain coarsening of wet snow. Ann. Glaciol., 18, 129-134.

Raymond, C.F. and K. Tusima. 1979. Grain coarsening of watersaturated snow. J. Glaciol., 22(86), 83-105.

Robin, G.deQ. 1983. The climatic record in polar ice sheets. Cambridge, Cambridge University Press.

Shoji, H. and C.C. Langway, Jr. 1989. Physical property reference horizons. In Oeschger, H. and C.C. Langway, Jr, eds. The environmental record in glaciers and ice sheets. Chichester, etc., John Wiley and Sons, 161-175.

Thompson, L.G., X. Wu, E. Mosley-Thompson and Z. Xie. 1988. Climatic records from the Dunde ice cap, China. Ann. Glaciol., 10, 178-182.

Wakahama, G. 1964. [Metamorphisms of wet snow.] Low Temp. Sci. 23, 51-66. [In Japanese with English summary.]

Wakahama, G., T. Nakamura and Y. Endo. 1968. [Infiltration of melt water into snow cover. 2.] Low Temp. Sci. 26, 53-76. [In Japanese with English summary.]

\section{APPENDIX}

Substituting Equations (5) and (6) into Equation (7) gives:

$\frac{\mathrm{d}}{\mathrm{d} f}\left\{(1-w)\left[\delta_{\mathrm{i} 0}(1-f)+\int_{0}^{f} \delta_{\mathrm{i}} \mathrm{d} f\right]+w\left[\frac{1}{\alpha}\left(1+\delta_{\mathrm{i}}\right)-1\right]\right\}$ $=0$.
Refining this equation gives:

$$
\mathrm{d} f=\frac{w}{\alpha(1-w)\left(\delta_{\mathrm{i} 0}-\delta_{\mathrm{i}}\right)} \mathrm{d} \delta_{\mathrm{i}} .
$$

Integrating both sides,

$$
\int \mathrm{d} f=\frac{w}{\alpha(1-w)} \int \frac{1}{\delta_{\mathrm{i} 0}-\delta_{\mathrm{i}}} \mathrm{d} \delta_{\mathrm{i}}
$$

So,

$$
\frac{\alpha(1-w)}{w} f=\ln \left(\delta_{\mathrm{i} 0}-\delta_{i}\right)+C .
$$

At initial condition $f=0$, the following equation is generated:

$$
\alpha\left(1+\delta_{\mathrm{w} 0}\right)=1+\delta_{\mathrm{i}} .
$$

This is substituted for Equation (A1):

$$
C=\ln \left[\left(\delta_{\mathrm{i} 0}+1\right)-\alpha\left(1+\delta_{\mathrm{w}}\right)\right] .
$$

Equation (A1) substitution of this is carried out:

$$
\mathrm{e}^{\frac{\alpha(1-w)}{w} f}=\frac{\left(1+\delta_{\mathrm{i} 0}\right)-\alpha\left(1+\delta_{\mathrm{w} 0}\right)}{\left(\delta_{\mathrm{i} 0}-\delta_{\mathrm{i}}\right)} .
$$

Rearranging gives:

$$
\delta_{\mathrm{i}}=\delta_{\mathrm{i} 0}-\exp \left[-\alpha\left(\frac{1-w}{w}\right) f\right]\left[\left(\delta_{\mathrm{i} 0}+1\right)-\alpha\left(\delta_{\mathrm{w} 0}+1\right)\right] .
$$

Substituting Equation (8) for Equation (5) gives:

$$
\begin{aligned}
\delta_{\mathrm{iz}}=\delta_{\mathrm{i} 0}+\frac{1}{\alpha}\left(\frac{w}{1-w}\right)\left[\left(\delta_{\mathrm{i} 0}+1\right)-\alpha\left(\delta_{\mathrm{w} 0}+1\right)\right] \\
\cdot\left\{\exp \left[-\alpha\left(\frac{1-w}{w}\right) f\right]-1\right\} .
\end{aligned}
$$

Substituting Equation (8) for Equation (6) gives:

$$
\begin{aligned}
& \delta_{\mathrm{w}}=\delta_{\mathrm{w} 0}+\frac{1}{\alpha}\left[\left(\delta_{\mathrm{i} 0}+1\right)-\right.\left.\alpha\left(\delta_{\mathrm{w} 0}+1\right)\right] \\
& \cdot\left\{1-\exp \left[-\alpha\left(\frac{1-w}{w}\right) f\right]\right\} .
\end{aligned}
$$

